\title{
Charge Transport and Rectification in Arrays of SAM-Based Tunneling Junctions
}

\section{Citation}

Nijhuis, Christian A., William F. Reus, Jabulani R. Barber, Michael D. Dickey, and George M.

Whitesides. 2010. Charge transport and rectification in arrays of SAM-based tunneling junctions. Nano Letters 10(9): 3611-3619.

\section{Published Version}

doi:10.1021/nl101918m

\section{Permanent link}

http://nrs.harvard.edu/urn-3:HUL.InstRepos:9896817

\section{Terms of Use}

This article was downloaded from Harvard University's DASH repository, and is made available under the terms and conditions applicable to Open Access Policy Articles, as set forth at http:// nrs.harvard.edu/urn-3:HUL.InstRepos:dash.current.terms-of-use\#OAP

\section{Share Your Story}

The Harvard community has made this article openly available.

Please share how this access benefits you. Submit a story.

Accessibility 


\title{
Charge Transport and Rectification in Arrays of SAM-Based
}

\section{Tunneling Junctions}

Christian A. Nijhuis, William F. Reus, Jabulani R. Barber, Michael D. Dickey, and George M. Whitesides*

Department of Chemistry and Chemical Biology, Harvard University, 12 Oxford St, Cambridge, MA 02138, USA

Corresponding author:

Tel.: 6174589430

Fax: 6174589857

e-mail: gwhitesides@gmwgroup.harvard.edu

\begin{abstract}
This paper describes a fabrication method that generates small arrays of tunneling junctions based on self-assembled monolayers (SAMs) with liquid metal topelectrodes and ultra-flat bottom-electrodes; the yield of junctions in this method is high (70-90\%). These junctions incorporate SAMs of alkanethiolates with ferrocene termini (11-(ferrocenyl)-1-undecanethiol, $\mathrm{SC}_{11} \mathrm{Fc}$ ), and rectify currents with large rectification ratios $(R)$ of $R=90-180$. These values are larger than predicted by theory $(R \sim 20)$, and larger than previous experimental measurements. SAMs of n-alkanethiolates without the
\end{abstract} Fc groups $\left(\mathrm{SC}_{\mathrm{n}-1} \mathrm{CH}_{3}\right.$, with $\mathrm{n}=12,14,16$, or 18$)$ do not rectify $(R=1.0-5.0)$. These arrays enable the measurement of the electrical characteristics of the junctions as a 
function of chemical structure, voltage, and temperature, over the range of $90-293 \mathrm{~K}$, with statistically large numbers of data $(\mathrm{N}=300-800)$. Rectification with Fc-terminated SAMs seems to be based on a mechanism of charge transport that changes with bias: from tunneling (at one bias), to hopping combined with tunneling (at the opposite bias).

\section{Introduction}

Molecular electronics ${ }^{1}$ originally promised that molecule(s) bridging two or more electrodes would generate electronic function, and overcome the scaling limits of conventional semiconductor technology. ${ }^{2}$ So far, there have been no commercially successful electronic devices employing small molecules as the active element. Fabricating even simple molecular circuits that incorporate more than a handful of molecules is a challenge: most fabrication techniques have low yields, ${ }^{3}$ produce junctions that are dominated by artifacts ${ }^{4}$ (especially conducting filaments ${ }^{5,6,7,8}$ ), and generate too few reliable data for statistical analysis (the work of Lee et al. provides an exception ${ }^{9}$ ). Largely absent are physical-organic studies connecting molecular structure and electrical properties, and studies that include measurements as a function of temperature measurements necessary to determine the mechanism(s) of charge transport across SAMbased junctions (the work of Allara et al..$^{10}$ and Tao et al. ${ }^{11}$ provide examples of successful studies). Here we describe a technique that generates small arrays (seven junctions) of SAM-based junctions with satisfactory yields (70-90\%) of working devices; this technique makes it possible to conduct physical-organic studies with statistically large numbers of data $(\mathrm{N}=400-800)$, and to do so over a range of temperatures $(T)$ from 90 to $293 \mathrm{~K}$. 
We describe two systems. i) Junctions based on SAMs of n-alkanethiolates $\left(\mathrm{SC}_{\mathrm{n}-1} \mathrm{CH}_{3}\right)$; these junctions show, as expected, ${ }^{4}$ tunneling as the dominant mechanism of charge transport. ii) Junctions based on SAMs of alkanethiolates terminated with ferrocene (11-(ferrocenyl)-1-undecanethiol, $\mathrm{SC}_{11} \mathrm{Fc}$ ) groups; these junctions rectify currents, and thus act as molecular diodes with rectification ratios $R \approx 1.3 \times 10^{2}$ (eq. 1). In equation $1, J=$ current density $\left(\mathrm{A} / \mathrm{cm}^{2}\right)$ and $V=$ voltage $(\mathrm{V})$.

$$
R \equiv|J(-1.0 \mathrm{~V}) / J(+1.0 \mathrm{~V})|
$$

Studying the rectification ratios, rather than current densities, has the advantage that the current measured in one direction of bias serves as a reference for the current measured at the opposite bias and, thus, eliminates many of the uncertainties related to contact resistances or contact areas. The junction at one bias is the reference for the junction at the opposite bias.

Most research, both theoretically and experimentally, that has had the objective of developing the molecular analogue of a diode has been based on the so-called "electron donor-bridge-acceptor" compounds described in a seminal paper by Aviram and Ratner. ${ }^{12}$ Tunneling junctions incorporating these molecules, ${ }^{13,14,15}$ and others, ${ }^{16,17}$ (including one example reported by $\mathrm{us}^{18}$ ) have rectified currents, but neither the mechanism of charge transport nor the origin of the observed rectification have been unambiguously established in any junction. Four factors underlie this ambiguity: i) structural information on SAMs only exists for a relatively small number of molecular precursors $;{ }^{19}$ virtually no structural information is available for SAMs incorporating molecules with the donorbridge-acceptor architecture, due to their structural complexity. ii) Asymmetries other than an electric dipole, present in either the SAMs themselves or in the junctions, can 
contribute to rectification; ${ }^{20}$ many of the previous studies do not rule out these other possible sources of rectification using appropriate controls and statistics. iii) The reported rectification ratios have typically been low $\left(1<R<5 .{ }^{16,17,18}\right)$. Without adequate statistical support, most of these values are not distinguishable from $R \sim 1$. iv) $J(\mathrm{~V})$ measurements as a function of temperature have not been conducted. ${ }^{10,11,21}$

These studies, as a group, have not considered molecular rectifiers in which a change occurs in the mechanism of charge transport (e.g., from tunneling to hopping) as applied bias switches from one direction to the other; we believe that such junctions have the potential to yield large rectification ratios $\left(R>10^{2}\right)$.

\section{Fabrication of the Devices}

We have reported that a eutectic alloy of gallium and indium (EGaIn) with its superficial layer of $\mathrm{Ga}_{2} \mathrm{O}_{3}$, can be molded into cone-shaped tips that are useful to form electrical contacts with $\mathrm{SAMs}^{22,23}$ : the properties of $\mathrm{Ga}_{2} \mathrm{O}_{3} / \mathrm{EGaIn}$ resemble that of a nonNewtonian fluid. ${ }^{24}$ This method affords SAM-based junctions, with high yields of working devices, and enables statistical analysis through the collection of large numbers of data. These junctions - with the top-electrode suspended from a syringe - are convenient to use, but they lack the encapsulation and addressability needed to operate in a pressure- and temperature-controlled chamber.

Figure 1 outlines the method, based on $\mathrm{Ga}_{2} \mathrm{O}_{3} / \mathrm{EGaIn}$, that we used to construct arrays of SAM-based tunneling junctions that i) are mechanically stable, ii) do not suffer from alloying between metal electrodes, iii) do not require metal deposition either by electronbeam evaporation or by sputtering directly onto SAMs, iv) do not require intermediate 
layers of conducting polymers, or rigorous/empirical processing steps, and v) make it possible to perform $J(\mathrm{~V})$ measurements as a function of temperature over a broad range of temperatures $(90-293 \mathrm{~K})$. This method uses $\mathrm{Ga}_{2} \mathrm{O}_{3} / \mathrm{EGaIn}$, stabilized in microchannels in a transparent polymer (PDMS), as a liquid metal top-electrode (see Methods). Figure 2 shows optical micrographs of a complete device.

Figs. $1 \mathrm{~F}$ and $1 \mathrm{G}$ show idealized views of the junctions. In reality, the SAMs have defects due to i) step edges, ii) phase boundaries, iii) pin holes, iv) impurities, and v) grain boundaries. ${ }^{19}$ To reduce the number of defects in the SAM relative to the number present in the rough top-surface of evaporated silver, we used ultra-flat, template-striped silver $\left(\mathrm{Ag}^{\mathrm{TS}}\right)$ electrodes embedded in cured optical adhesive (OA) ${ }^{25}$ It is important to embed the electrodes in OA to prevent free-standing structures of Ag on the wafer, with edges at which the SAMs can not pack densely, ${ }^{26}$ that may cause shorts once the channels are filled with $\mathrm{Ga}_{2} \mathrm{O}_{3} / \mathrm{EGaIn}$.

The atomic force micrograph shows two important characteristics of these electrodes (Fig. 2). i) The difference in height between the OA and Ag electrodes was insignificant $(<0.1 \mathrm{~nm})$. ii) The $\mathrm{Ag}^{\mathrm{TS}}$ electrodes were smooth and had a root-mean-square surface roughness of $0.9 \mathrm{~nm}$ (approximately two lattice planes of silver) measured over $25 \times 25$ $\mu \mathrm{m}^{2}$, but the $\mathrm{Ag}^{\mathrm{TS}} / \mathrm{OA}$ interface did not seal completely with the OA at their edges: the gap at the $\mathrm{Ag}^{\mathrm{TS}} / \mathrm{OA}$-interface was $150 \mathrm{~nm}$ wide and $6.0 \mathrm{~nm}$ deep, with a surface roughness of $5.8 \mathrm{~nm}$ (averaged over $5.0 \times 0.1 \mu \mathrm{m}^{2}$ ). 
Figure 1: Fabrication of the arrays of SAM-based tunneling junctions. The schematic representations are not drawn to scale. A) We fabricated the pattern of Ag-electrodes using photolithography, electron-beam deposition of silver, and lift-off. B) Using a UVcurable adhesive, we affixed a glass substrate to the pattern of the silver electrodes. The cured optical adhesive interacts strongly with the Ag and the glass support, but not with the wafer. C) We cleaved the Ag/adhesive/glass composite from the wafer by applying a razor blade - with gentle pressure in a direction parallel to the wafer - between the glass substrate and the wafer. D) We aligned a microchannel in PDMS perpendicular to the electrodes after we formed the SAMs on these electrodes. E) We filled the microchannels with $\mathrm{Ga}_{2} \mathrm{O}_{3} /$ EGaIn to complete the device. F) and $\mathrm{G}$ ) show schematic, idealized representations of the two side views of the junctions with a $\mathrm{SAM}$ of $\left.\mathrm{SC}_{11} \mathrm{CH}_{3} . \mathrm{H}\right) \mathrm{A}$ schematic representation of the $\mathrm{Ag}^{\mathrm{TS}} / \mathrm{OA}$ interface. The gap between the $\mathrm{OA}$ and the $\mathrm{Ag}^{\mathrm{TS}}$ (indicated by the red arrow), probably caused by shrinkage of the polymer during polymerization, is $150 \mathrm{~nm}$ wide and $6 \mathrm{~nm}$ deep. The SAMs will be disordered at the edge of the electrode; this disordered region has the potential to be a source of defects in the junctions. We believe that the surface tension of $\mathrm{Ga}_{2} \mathrm{O}_{3} / \mathrm{EGaIn}$ (surface tension of $\mathrm{Ga}_{2} \mathrm{O}_{3} / \mathrm{EGaIn}$ is $624 \mathrm{mN} / \mathrm{m}^{27}$ ) prevents it from filling the gap (filled with air) between the $\mathrm{AO}$ and the $\mathrm{Ag}^{\mathrm{TS}}$, but we have no direct evidence to support this belief. 

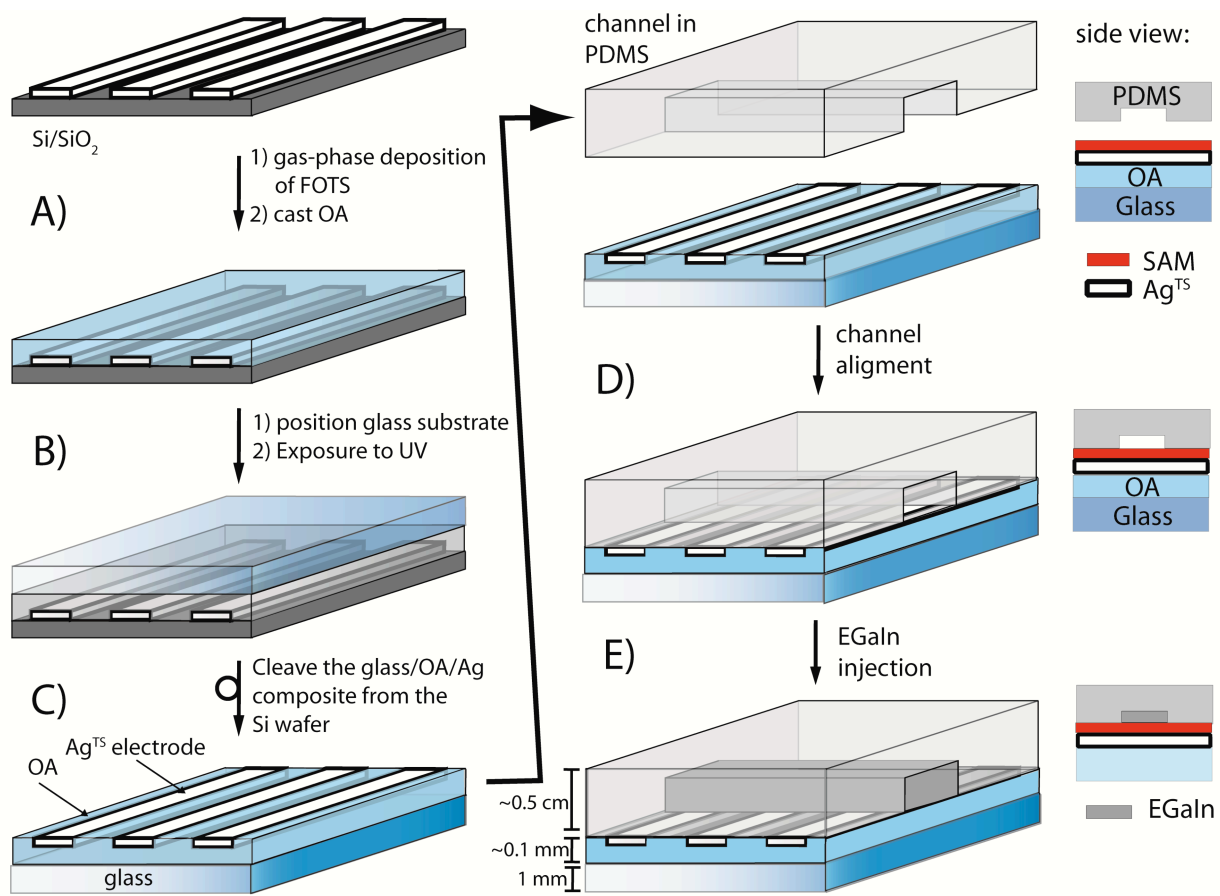

Cross section perpendicular to channel:

F)

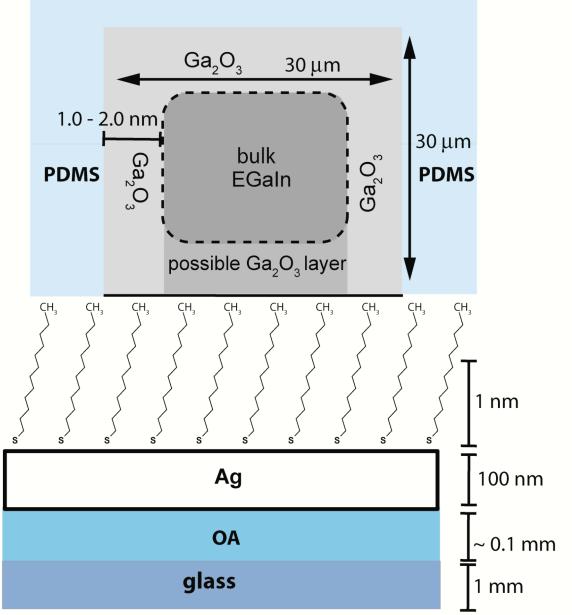

Cross section parallel with channel:

G)

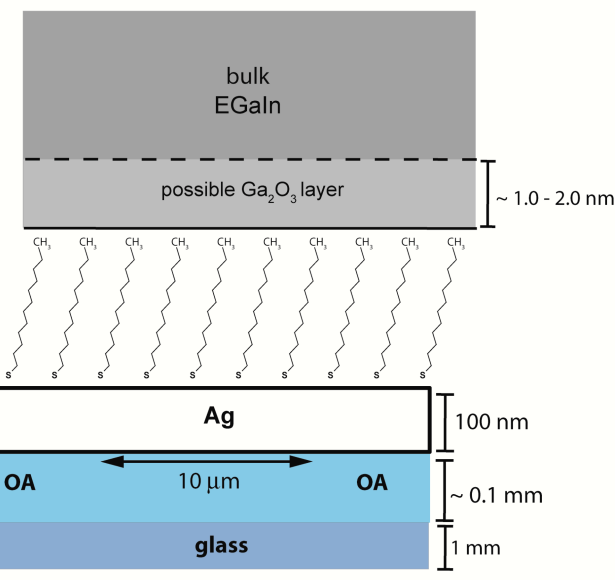

The $\mathrm{Ag}^{\mathrm{TS}} / \mathrm{OA}$ interface:

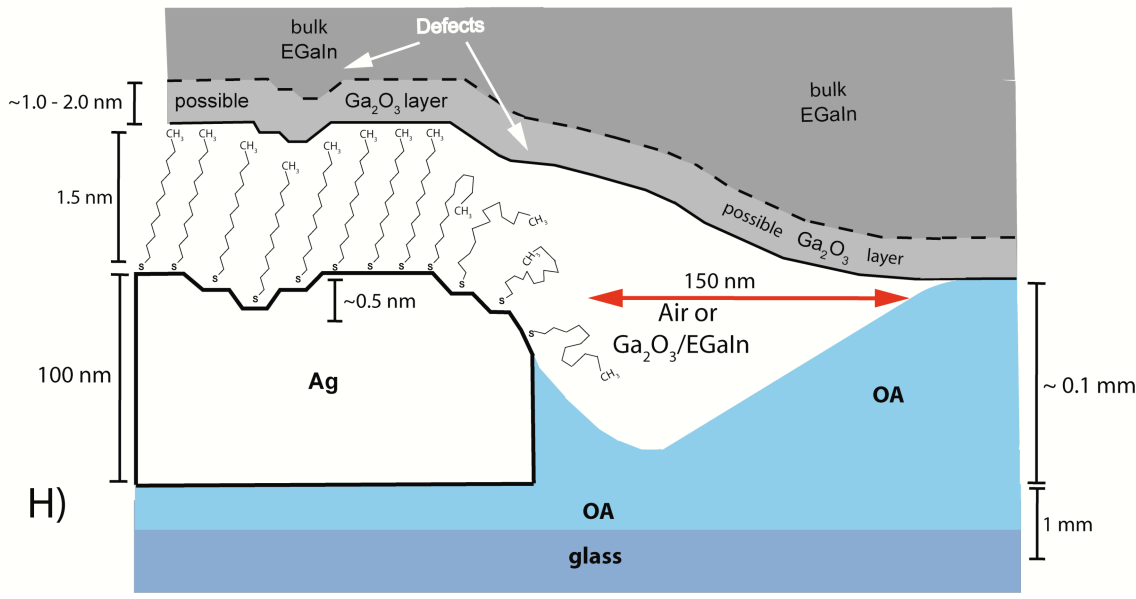


Figure 2: Atomic force microscopy images of the $\mathrm{Ag}^{\mathrm{TS}}$ electrodes and optical micrographs of a complete device. A) Atomic force micrograph of the $\mathrm{Ag}^{\mathrm{TS}} / \mathrm{AO}$ interface. B) Optical micrograph of a complete device. C) Magnification of two junctions. 

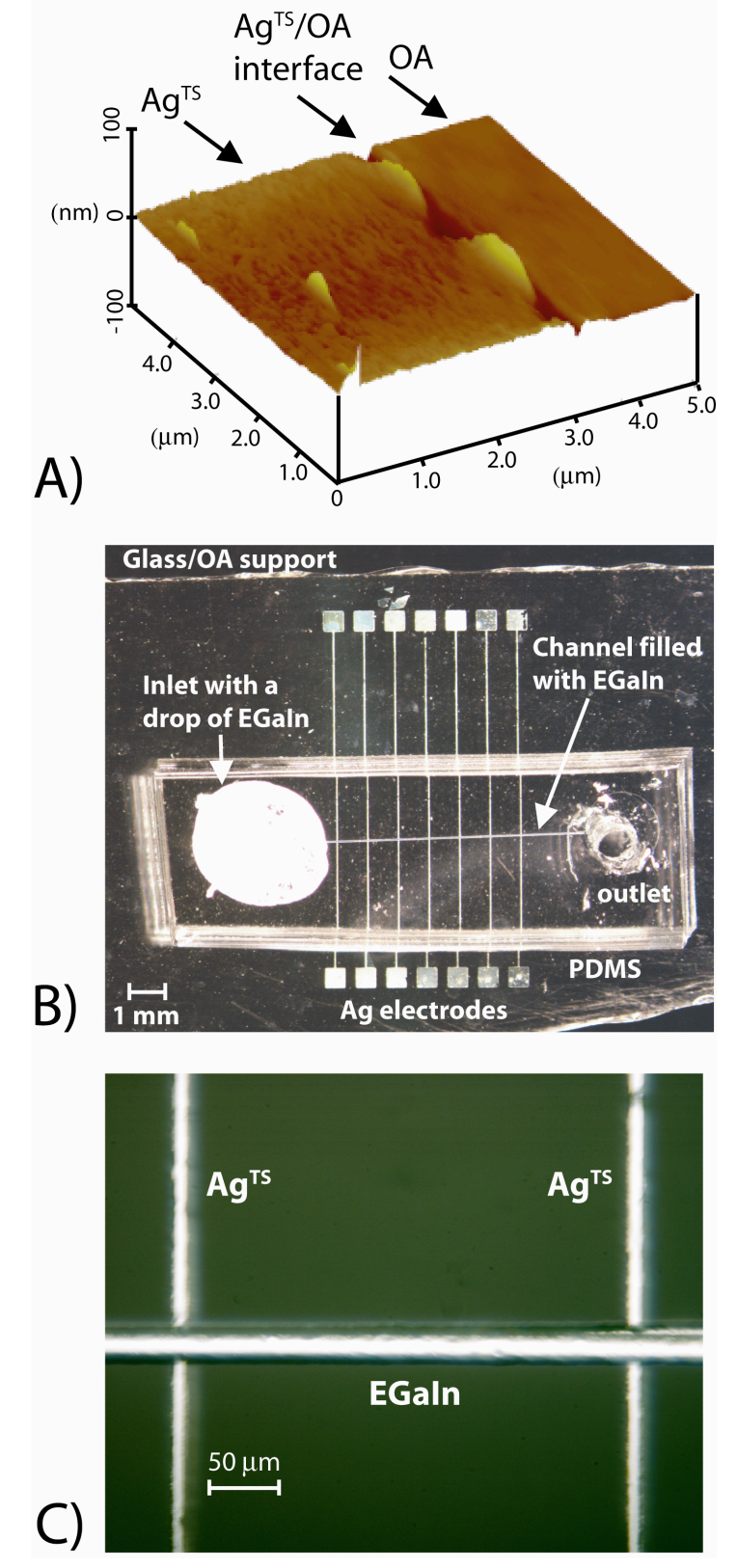
This procedure, thus, generates embedded electrodes that are flat, but the topography at the interface between the metal and $\mathrm{OA}$ is not completely smooth. Figure $1 \mathrm{H}$ sketches this $\mathrm{AO} / \mathrm{Ag}^{\mathrm{TS}}$ interface schematically.

\section{Statistical Analysis.}

To account for defects in the tunneling junctions, to discriminate artifacts from real data, and to determine the yields of working devices, we believe it is essential to collect, and to analyze statistically, large numbers of data. ${ }^{9}$ Although statistical analyses are common in (and an essential part of) studies involving break junctions, ${ }^{30}$ and junctions involving scanning probes, ${ }^{11}$ Lee et al. ${ }^{9}$ was the first to address, with statistical analysis of many data, the shortcomings of SAM-based junctions having evaporated metal topelectrodes prepared using the very low-yielding procedures reported in most prior work.

We used a procedure for the statistical analysis of the data that we have described previously (see Additional Information and Methods). ${ }^{23}$ We constructed histograms of all values of $J$ for each measured potential. We fitted all our data to single Gaussian functions using a non-linear least squares fitting procedure to obtain the log-mean value of $J$ for each measured potential, and its log-standard deviation. We emphasize that no data are omitted: we have not selected data.

\section{Junctions with $\mathrm{SAMs}$ of $\mathrm{SC}_{\mathrm{n}-1} \mathrm{CH}_{3}$}

Figures 3A and B show, as expected from a large body of previous work, that the current density through SAMs of alkanethiols ${ }^{4,9,31,32,33}$ i) depends exponentially on the thickness $(d(\AA))$ of the SAM, ii) depends linearly on the bias in the low-bias regime, and 
iii) is independent of the temperature $T$. All these observations indicate that the mechanism of charge transport is tunneling. The tunneling decay coefficient $\beta\left(\AA^{-1}\right)$ can be determined using eq. $2\left(J_{0}\left(\mathrm{~A} / \mathrm{cm}^{2}\right)\right.$ is a constant that depends on the system and includes contact resistance).

$$
J=J_{0} e^{-\beta d}
$$

We found that $\beta=0.80 \pm 0.2 \AA^{-1}$ (or $\beta=1.0 \pm 0.2$ per $\mathrm{CH}_{2}$ ) with $J_{0}=6.3 \times 10^{2} \mathrm{~A} / \mathrm{cm}^{2}$ at a bias of $-0.5 \mathrm{~V}$ and $\beta=0.74 \pm 0.2 \AA^{-1}$ (or $\beta=0.93 \pm 0.2$ per $\mathrm{CH}_{2}$ ) with $J_{0}=21 \mathrm{~A} / \mathrm{cm}^{2}$ at $-0.2 \mathrm{~V}$; both values of $\beta$ are within the range reported for similar compounds, ${ }^{4}$ including those obtained with cone-shaped tips of $\mathrm{Ga}_{3} \mathrm{O}_{2} / \mathrm{EGaIn}^{22}$ (Our initial description $^{22}$ of these cone-shaped electrodes gave values of $J$ that we interpreted to indicate a significantly lower value: $\beta=0.6$ per $\mathrm{CH}_{2}$. We now believe this interpretation was incorrect, and that a value of $\beta=1.0$ per $\mathrm{CH}_{2}$ is correct. We will discuss the origin of this error in a separate paper. ${ }^{34}$ ). Figure $3 \mathrm{~A}$ shows a temperature-dependent measurement of $J(\mathrm{~V})$ of a $\mathrm{Ag}^{\mathrm{TS}}-\mathrm{SC}_{13} \mathrm{CH}_{3} / / \mathrm{Ga}_{2} \mathrm{O}_{3} / \mathrm{EGaIn}$ junction (see Methods; “TS", = template stripped). The devices we used in this study could be cooled from $293 \mathrm{~K}$ to $110 \mathrm{~K}$, and warmed again to $293 \mathrm{~K}$, without changing their $J(\mathrm{~V})$ characteristics (in vacuum at $1 \times 10^{-}$ ${ }^{6}$ bar). From this experiment we conclude that neither i) solidification of EGaIn at $\sim 250$ $\mathrm{K}$, nor ii) the differences between the thermal expansion coefficients for PDMS $\left(3 \times 10^{-}\right.$ $\left.{ }^{4} / \mathrm{K}\right),{ }^{35}$ glass $\left(0.08 \times 10^{-4} / \mathrm{K}\right),{ }^{36} \mathrm{Ga}_{2} \mathrm{O}_{3}\left(0.042 \times 10^{-4} \mathrm{~K}^{-1}\right),{ }^{37} \mathrm{Ag}\left(0.18 \times 10^{-4} / \mathrm{K}\right),{ }^{38}$ and EGaIn $\left(1.1 \times 10^{-4} / \mathrm{K}\right)^{39}$ cause shorts, lead to loss of contact, or alter the device characteristics in destructive ways. 
Figure 3: Current density measurements of $\mathrm{Ag}^{\mathrm{TS}}-\mathrm{SC}_{13} \mathrm{CH}_{3} / / \mathrm{Ga}_{2} \mathrm{O}_{3} / \mathrm{EGaIn}$ and $\mathrm{Ag}^{\mathrm{TS}}$ $\mathrm{SC}_{11} \mathrm{Fc} / / \mathrm{Ga}_{2} \mathrm{O}_{3} / \mathrm{EGaIn}$ junctions. A) Four $J(\mathrm{~V})$ curves of a $\mathrm{Ag}^{\mathrm{TS}}-\mathrm{SC}_{13} \mathrm{CH}_{3} / / \mathrm{Ga}_{2} \mathrm{O}_{3} / \mathrm{EGaIn}$ junction measured at four different temperatures $(T=110,190,250$, and $293 \mathrm{~K})$ in vacuum $\left(1 \times 10^{-6}\right.$ bar $)$. Inset, the current density vs. the voltage in the low-bias regime (0.10 to $0.10 \mathrm{~V})$. B) The values of $J$ measured at -0.5 and $-0.2 \mathrm{~V}$ as a function of the length of the SAM. The black, solid lines are fits to eq. 2. C) A semi-log plot of the average absolute value of the current density vs. the voltage of $\mathrm{Ag}^{\mathrm{TS}}$ $\mathrm{SC}_{11} \mathrm{Fc} / / \mathrm{Ga}_{2} \mathrm{O}_{3} / \mathrm{EGaIn}$ junctions. The error bars indicate the log-standard deviation. At low voltages we observed a non-zero current (see Additional information). The current could involve oxidation-reduction processes of the Fc moieties. We did not observe (or perhaps too small to be observed) those currents in junctions with SAMs of $\mathrm{SC}_{\mathrm{n}-1} \mathrm{CH}_{3}$. Inset, the histogram of the rectification ratios with a Gaussian fit to this histogram. We did not select data prior to analysis, and the Gaussian function is a fit to all data (see additional information for details). D) Three $J(\mathrm{~V})$ curves measured at three different temperatures $(T=110,250$, and $293 \mathrm{~K})$. 

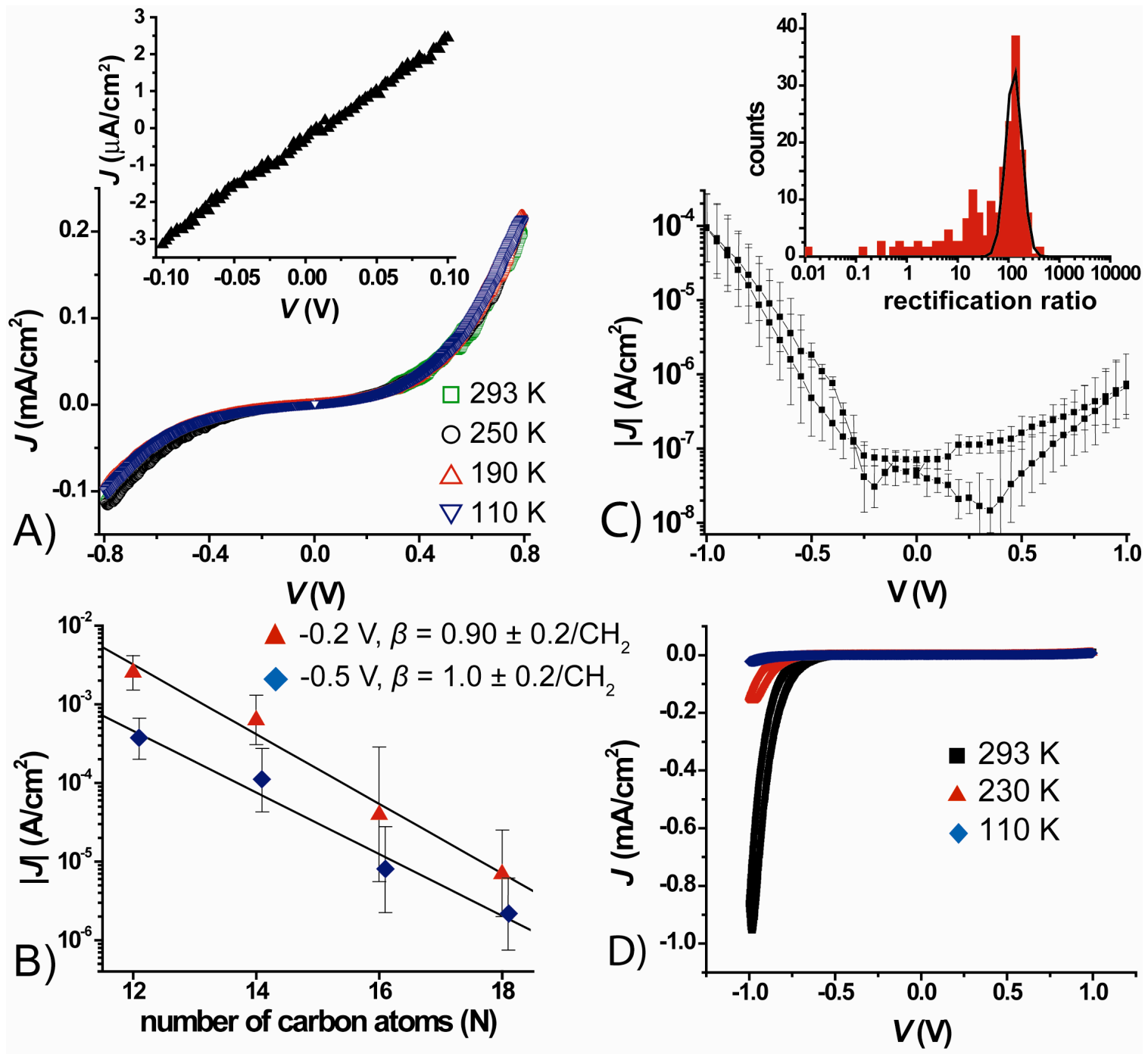


\section{The Layer of $\mathrm{Ga}_{2} \mathrm{O}_{3}$}

The junctions have three uncertainties all related to the layer of $\mathrm{Ga}_{2} \mathrm{O}_{3}$. i) The resistance of the layer of $\mathrm{Ga}_{2} \mathrm{O}_{3}$ : we estimated the resistance of the layer of $\mathrm{Ga}_{2} \mathrm{O}_{3}$ and concluded that the resistance is approximately four orders of magnitude less than that of a $\mathrm{SAM}$ of $\mathrm{SC}_{10} \mathrm{CH}_{3}$ (see Additional Information). ${ }^{23}$ ii) The thickness of the layer of $\mathrm{Ga}_{2} \mathrm{O}_{3}$ : we measured the thickness of the layer of $\mathrm{Ga}_{2} \mathrm{O}_{3}$ on a drop of $\mathrm{Ga}_{2} \mathrm{O}_{3} / \mathrm{EGaIn}$ to be less than $2.0 \mathrm{~nm}$ (see Additional Information). ${ }^{24}$ iii) The topography of contact of $\mathrm{Ga}_{2} \mathrm{O}_{3} / E$ EaIn with the $S A M$ : we recorded optical micrographs of the $\mathrm{Ga}_{2} \mathrm{O}_{3} / \mathrm{EGaIn}$ in microchannels in PDMS sealed against glass surfaces which suggest that the $\mathrm{Ga}_{2} \mathrm{O}_{3} / \mathrm{EGaIn}$ forms a conformal contact with the glass surface.

We believe that a layer of $\mathrm{Ga}_{2} \mathrm{O}_{3}$ at the PDMS interface forms during filling of the channels, since PDMS is permeable to oxygen. ${ }^{24}$ This layer interacts strongly with the walls of the microchannel and is important for stabilizing the EGaIn in the microchannel (EGaIn has a higher surface tension than $\mathrm{Hg}$, but $\mathrm{Hg}$ - because its surface tension is not lowered by formation of an oxide layer -- does not form stable features in microchannels in PDMS). ${ }^{24}$ We have no direct evidence describing the interface between the $\mathrm{Ga}_{2} \mathrm{O}_{3} /$ EGaIn and the SAM, but we infer that a discontinuous layer of $\mathrm{Ga}_{2} \mathrm{O}_{3}$ forms at this interface (see Additional Information). In our discussions we assume that the layer of $\mathrm{Ga}_{2} \mathrm{O}_{3}$ is present. In any case, a layer of $\mathrm{Ga}_{2} \mathrm{O}_{3}$ may influence the values of $J$, but it will not influence the value of $R$, because the value of $R$ is the ratio of the current densities measured at opposite bias across the same junction (eq. 1).

\section{Junctions with SAMs of $\mathrm{SC}_{11} \mathrm{Fc}$}


Figure $3 \mathrm{C}$ shows the average current density as a function of voltage for the $\mathrm{Ag}^{\mathrm{TS}}$ $\mathrm{SC}_{11} \mathrm{Fc} / / \mathrm{Ga}_{2} \mathrm{O}_{3} / \mathrm{EGaIn}$ junctions, and the histogram of the rectification ratios with a Gaussian fit to this histogram. These junctions show large rectification ratios (eq. $1, R \approx$ $1.3 \times 10^{2}$ with a log-standard deviation of 1.4$)$. Thus, $68 \%$ of the log-normal distribution of $R$ lies within the interval $(90,180)$.

The junctions have three sources of asymmetry that may contribute to the rectification. i) The two contacts between the electrodes and the SAMs differ: the $\mathrm{Ga}_{2} \mathrm{O}_{3} /$ EGaIn top-electrode forms a van der Waals contact, and the silver bottomelectrode forms a covalent Ag-S- $\mathrm{CH}_{2}$ contact. ii) The top- $\left(\mathrm{Ga}_{2} \mathrm{O}_{3} / \mathrm{EGaIn}\right)$ and bottom(Ag) electrodes may have different work functions $\left(\Phi_{\mathrm{Ag}} \approx \Phi_{\mathrm{EGaIn}} \approx 4.5 \mathrm{eV}\right.$, but the work functions of each surface may be modified by the SAM or $\mathrm{Ga}_{2} \mathrm{O}_{3}$, respectively). iii) A layer of $\mathrm{Ga}_{2} \mathrm{O}_{3}$ is present only on the top-electrode, and not on the bottom-electrode. We believe that the rectification in the $\mathrm{Ag}^{\mathrm{TS}}-\mathrm{SC}_{11} \mathrm{Fc} / / \mathrm{Ga}_{2} \mathrm{O}_{3} / \mathrm{EGaIn}$ junctions is due to the molecules, and not to any other asymmetries in our junctions or redox reactions involving Fc and $\mathrm{GaO}_{\mathrm{x}}{ }^{23}$ for two reasons: i) junctions lacking the Fc moiety - e.g., with SAMs of $\mathrm{SC}_{\mathrm{n}-1} \mathrm{CH}_{3}-$ do not rectify; thus, neither the layer of $\mathrm{Ga}_{2} \mathrm{O}_{3}$ itself nor any other asymmetries in the junctions cause rectification. ii) Two types of junctions with SAMs of $\mathrm{SC}_{11} \mathrm{Fc}$ having top-electrodes other than $\mathrm{Ga}_{2} \mathrm{O}_{3} / \mathrm{EGaIn}$ - namely, a tungsten STM tip ${ }^{46}$ and a redox-inactive $\mathrm{Au}$ foil ${ }^{23}$ - also rectified currents with values of $R \sim 10-100$. $^{2}$

\section{Temperature-Dependent Measurements of $\mathrm{Ag}^{\mathrm{TS}}-\mathrm{SC}_{11} \mathrm{Fc} / / \mathrm{Ga}_{2} \mathrm{O}_{3} / \mathbf{E G a I n} \mathrm{Junctions}$}

To clarify the mechanisms of charge transport across the $\mathrm{Ag}^{\mathrm{TS}}-\mathrm{SC}_{11} \mathrm{Fc} / / \mathrm{Ga}_{2} \mathrm{O}_{3} / \mathrm{EGaIn}$ junctions, we measured the dependence of $J(\mathrm{~V})$ on temperature. Figure 3D shows three 
$J(\mathrm{~V})$ curves measured at 110, 230, and $293 \mathrm{~K}$ and Fig. 4A shows both the values of $J$ at $+1.0 \mathrm{~V}$ and $-1.0 \mathrm{~V}$ for the $\mathrm{Ag}^{\mathrm{TS}}-\mathrm{SC}_{11} \mathrm{Fc} / / \mathrm{Ga}_{2} \mathrm{O}_{3} / \mathrm{EGaIn}$ junctions measured at $T=110$ to $293 \mathrm{~K}$. The values of $J$ depend on $T$ at negative bias, but are independent of $T$ at positive bias. This observation indicates that tunneling (which is temperature independent) is the dominant mechanism of charge transport at positive bias, while hopping (which follows an Arrhenius dependence on temperature, see below) is the dominant mechanism of charge transport at negative bias. This observation also illustrates the value of examination of rectification: whatever the uncertainties about a junction, its behavior at one bias is an excellent control for its behavior at opposite bias. Here, the comparison of forward and reverse bias at different temperatures supports the conclusion that cooling the devices does not introduce artifacts into our measurements.

Figure 4 shows the Arrhenius plots of the $\mathrm{Ag}^{\mathrm{TS}}-\mathrm{SC}_{11} \mathrm{Fc} / / \mathrm{Ga}_{2} \mathrm{O}_{3} / \mathrm{EGaIn}$ junction at potentials in the range of -0.40 to $-1.0 \mathrm{~V}$ and 0.40 to $1.0 \mathrm{~V}$. This plot yields three important pieces of information. i) Hopping is only observed between -0.60 and $-1.0 \mathrm{~V}$, while at all other measured potentials the dominant mechanism of charge transport is tunneling; this observation suggests that at $-0.60 \mathrm{~V}$ the $\mathrm{HOMO}$ of the $\mathrm{Fc}$ begins to contribute to charge transport. ii) The activation energy, determined from the slope of the Arrhenius plot using eq. 3 (where the Boltzmann constant $k_{\mathrm{B}}=8.62 \times 10^{-5} \mathrm{eV} \mathrm{K}^{-1}$ ) is $E_{\mathrm{a}}=$ $77 \pm 5.3 \mathrm{meV}(7.4 \pm 0.51 \mathrm{~kJ} / \mathrm{mol})$ and is independent of the temperature. iii) At temperatures below $190 \mathrm{~K}, k_{\mathrm{B}} T \leq 16 \mathrm{meV}$ and is much smaller than $E_{\mathrm{a}}(77 \pm 5.3 \mathrm{meV})$. Hence, at $T<190 \mathrm{~K}$, tunneling is the dominant mechanism of charge transport over the entire range of applied bias $(-1.0 \mathrm{~V}$ to $1.0 \mathrm{~V})$.

$$
j=j_{0} \exp \left(-E_{a} / k_{B} T\right)
$$




\section{The Mechanism of Rectification}

All these observations can be rationalized by the model of charge transport proposed in Figure 5. This Figure shows proposed energy-level diagrams of the $\mathrm{Ag}^{\mathrm{TS}}-$ $\mathrm{SC}_{11} \mathrm{Fc} / / \mathrm{Ga}_{2} \mathrm{O}_{3} / \mathrm{EGaIn}$ junctions at biases of -1.0 and $1.0 \mathrm{~V}$. In all experiments, we biased the $\mathrm{Ga}_{2} \mathrm{O}_{3} / \mathrm{EGaIn}$ top-electrodes, and grounded the $\mathrm{Ag}^{\mathrm{TS}}$ bottom-electrode. The HOMO level of the $\mathrm{SC}_{11} \mathrm{Fc}$ is centered on the $\mathrm{Fc}$ moiety, and couples more strongly to the $\mathrm{Ga}_{2} \mathrm{O}_{3} / \mathrm{EGaIn}$ top-electrode than to the $\mathrm{Ag}^{\mathrm{TS}}$ bottom-electrode, because it is in van der Waals contact with the $\mathrm{Ga}_{2} \mathrm{O}_{3} /$ EGaIn electrode, but it is separated from the $\mathrm{Ag}^{\mathrm{TS}}$ electrode by the $\mathrm{SC}_{11}$ group. At positive bias, the Fermi level of the $\mathrm{Ga}_{2} \mathrm{O}_{3} / \mathrm{EGaIn}$ topelectrode decreases to below the value of the Fermi level of the $\mathrm{Ag}^{\mathrm{TS}}$ electrode. The HOMO of the Fc follows the Fermi level of the top-electrode, and therefore does not fall between the Fermi levels of the two electrodes. It does not participate in charge transport, but instead it becomes part of the tunneling barrier.

At negative bias, the Fermi level of the top-electrode increases, as does the HOMO of the Fc. At sufficiently negative bias, the HOMO of the Fc can overlap with both Fermi levels of the electrodes, and contribute to charge transport. We do not know all the details of the mechanism of charge transport, but we speculate that, when the HOMO level of the $\mathrm{Fc}$ is accessible, the first step involves an electron from the HOMO level of the Fc tunneling across the $\mathrm{SC}_{11}$ moiety (resulting in an $\mathrm{Fc}^{+}$-ion), and the second step involves an electron hopping across the Fc moiety, as suggested by the arrows (the arrows would point in the opposite direction in the case of hole transport). 
Figure 4: Thermally activated charge transport across $\mathrm{Ag}^{\mathrm{TS}}-\mathrm{SC}_{11} \mathrm{Fc} / / \mathrm{Ga}_{2} \mathrm{O}_{3} / \mathrm{EGaIn}$ junctions. A) The values of $J$ measured at -1.0 and $1.0 \mathrm{~V}$ as a function of temperature. Arrhenius plot of $\mathrm{Ag}^{\mathrm{TS}}-\mathrm{SC}_{11} \mathrm{Fc} / / \mathrm{Ga}_{2} \mathrm{O}_{3} / \mathrm{EGaIn}$ junction for values of $J$ measured at different potentials as a function of temperature in the range of $-0.40 \mathrm{~V}$ to $-1.0 \mathrm{~V}(\mathrm{~B})$ and 0.40 to $1.0 \mathrm{~V}(\mathrm{C})$. The red dashed vertical line indicates the temperature at which the EGaIn solidifies (as we could observe when we contacted the $\mathrm{Ga}_{2} \mathrm{O}_{2} / \mathrm{EGaIn}$ electrode with the probe). The solid black lines are fits to eq. 3 and indicate regimes where the mechanism of charge transport is dominated by hopping. The dashed black lines are guides to the eyes to indicate regimes where the mechanism of charge transport is dominated by tunneling. 

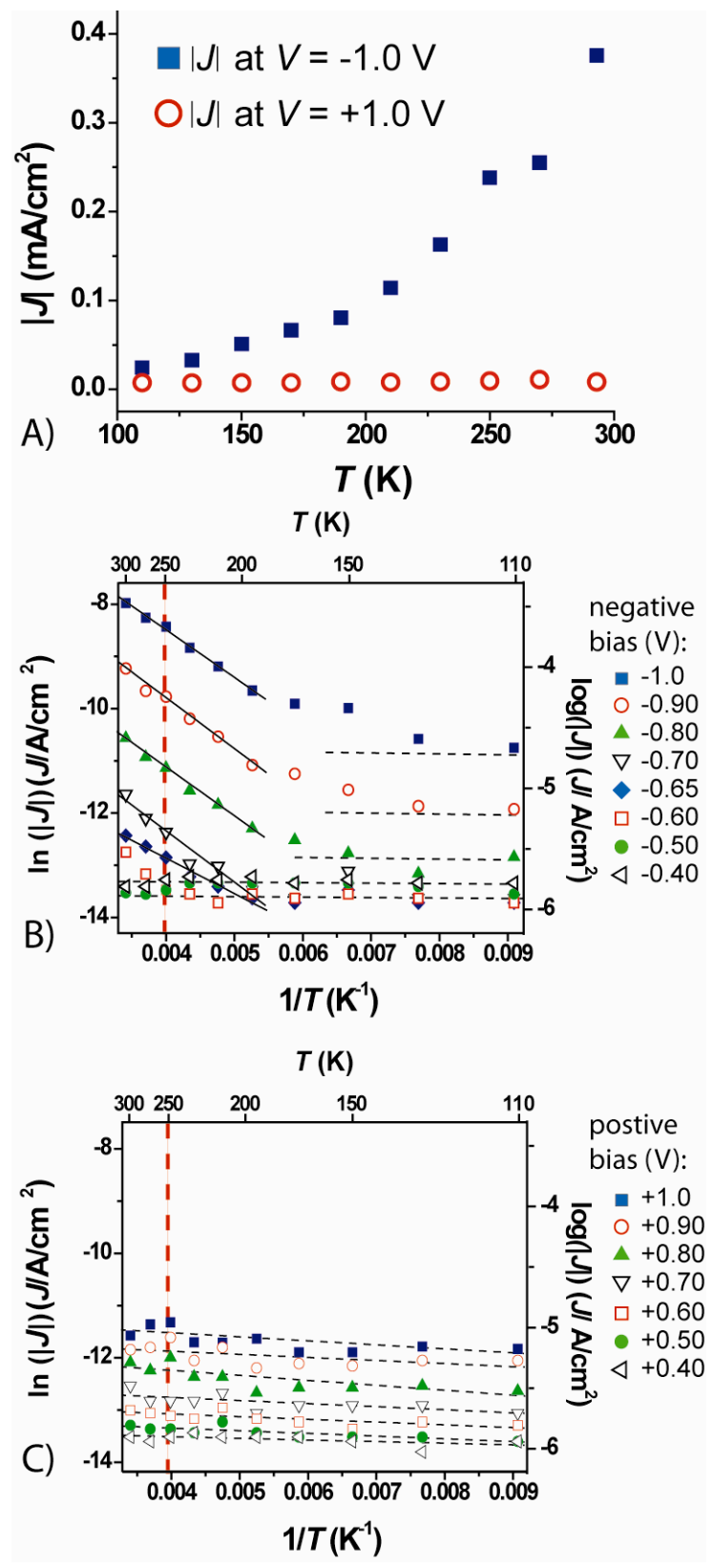
Activation of the hopping mechanism at negative bias led to values of $J$ that were two orders of magnitude higher (at room temperature) than those observed with tunneling alone at positive bias; thus, in our junctions, hopping is more efficient in the transport of charge than tunneling (Fig. 4). We infer that tunneling is the rate-limiting step in the transport of charge, and that the life-time of the $\mathrm{Fc}^{+}$species is probably short. We do not know how many $\mathrm{Fc}$ groups are oxidized at any given time, or how the $\mathrm{Fc}^{+}$-ions interact with $\mathrm{Ga}_{2} \mathrm{O}_{3}$-layer. The $\mathrm{Fc}^{+}$-ions will probably have a stronger interaction (perhaps ionic) with the $\mathrm{Ga}_{2} \mathrm{O}_{3}$-layer than neutral $\mathrm{Fc}$ moieties. We believe that the layer of $\mathrm{Ga}_{2} \mathrm{O}_{3}$ does not significantly affect the mechanism of charge transport across the SAMs (see above and Additional Information).

\section{The Large Value of $R$}

The large observed rectification ratio $(R \approx 130)$ for the $\mathrm{Ag}^{\mathrm{TS}}-\mathrm{SC}_{11} \mathrm{Fc} / / \mathrm{Ga}_{2} \mathrm{O}_{3} / \mathrm{EGaIn}$ junctions cannot be explained solely either by the presence of an asymmetrical tunneling barrier within the junction, or by citing the difference in potential drops across the Fc moiety and the alkyl chain. Theoretical studies incorporating either of these effects have suggested that for molecular tunneling junctions, the rectification ratios can not exceed $\sim$ $20{ }^{47}$ Those studies did not, however, consider a change in the mechanism of charge transport between forward and reverse bias as a mechanism that might result in high rectification ratios. 
Figure 5: Energy level diagram and mechanism of charge transport across $\mathrm{Ag}^{\mathrm{TS}}$ $\mathrm{SC}_{11} \mathrm{Fc} / / \mathrm{Ga}_{2} \mathrm{O}_{3} / \mathrm{EGaIn}$ junctions. The barrier widths of the junctions are defined by the lengths of the $\mathrm{C}_{11}$ alkyl chains and the Fc moiety. At positive bias, the arrows suggest that the charge traversing the junctions has to tunnel across the whole length of the molecule $\left(\mathrm{C}_{11}\right.$ alkyl chain and Fc group; a distance of $\left.2 \mathrm{~nm}\right)$, because the HOMO level of the Fc moiety does not overlap with the Fermi levels of the electrodes. At negative bias, the HOMO level of the Fc moiety can participate in charge transport, and the charge only has to tunnel across the $\mathrm{C}_{11}$ moiety over a distance of $1.3 \mathrm{~nm}$. In a second step, the charge can hop across the Fc moiety. We estimated the value of the HOMO level of the Fc moiety with wet electrochemistry (see Additional Information). 

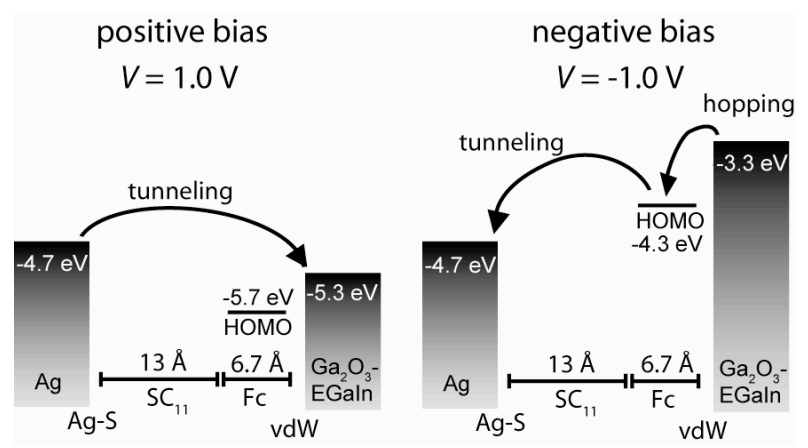
The values of $R$ can be rationalized by the fact that hopping (when $k_{\mathrm{B}} T \geq E_{\mathrm{a}}$ ) is more efficient in the transport of charge (i.e. allows for a higher current) than tunneling (Figure 4). When the HOMO of the Fc does not participate in charge transport, the charge must tunnel (elastically or inelastically) through the entire width of the junction, i.e., roughly the whole length of $\mathrm{SC}_{11} \mathrm{Fc}$ molecule defined by the lengths of the $\mathrm{SC}_{11}$ chain $\left(d_{\mathrm{SC} 11}, 1.3\right.$ $\mathrm{nm})$ and the $\mathrm{Fc}$ moiety $\left(d_{\mathrm{Fc}}, 0.66 \mathrm{~nm}\right)$. When the HOMO of the Fc falls between the Fermi levels of the electrodes, charge can tunnel from the HOMO of the $\mathrm{Fc}$ across the $\mathrm{C}_{11}$ chain, followed by hopping across the Fc moiety. This change in the mechanism of charge transport from tunneling to hopping effectively reduces the width of the tunneling barrier from $d_{\mathrm{SC} 11}+d_{\mathrm{Fc}}$ to $d_{\mathrm{SC} 11}$. Thus, the rectification ratio is approximately the ratio of the tunneling current densities across the whole $\mathrm{SAM}\left(J_{\mathrm{SC} 11 \mathrm{Fc}}\right)$ to the tunneling current density across the $\mathrm{SC}_{11}$ moiety $\left(J_{\mathrm{SC} 11}\right)$ and can be estimated using eq. $\mathbf{6}$ (with $\beta$ SC11 $=$ the decay constant across $\mathrm{SC}_{11}\left(\AA^{-1}\right.$, or per $\left.\mathrm{CH}_{2}\right)$ and $\beta_{\mathrm{Fc}}=$ the decay constant across the $\mathrm{Fc}$ moiety $\left(\AA^{-1}\right.$, or per $\left.\left.\mathrm{CH}_{2}\right)\right)$ :

$$
R=J_{S C_{11}} / J_{S C_{11} F_{c}} \propto \exp \left(-\beta_{S C_{11}} d_{S C_{11}}\right) /\left(\exp \left(-\beta_{S C_{11}} d_{S C_{11}}\right) \exp \left(-\beta_{F c} d_{F c}\right)\right)
$$

We do not know the value of $\beta_{\mathrm{Fc}}$, but have assumed $\beta_{\mathrm{alkyl}}=\beta_{\mathrm{Fc}}=0.80 \AA^{-1}$ (or 1.0 per $\mathrm{CH}_{2}$ ) to obtain a lower-limit value of $J_{S C_{11}} / J_{S C_{11} F c}=2.0 \times 10^{2}$. This semi-quantitative theoretical estimation of $R$ is compatible with the observed rectification ratio of $R \approx 1.3 \times$ $10^{2}$. This proposed model also agrees with the observation that the rectification ratios are close to unity at temperatures less than $190 \mathrm{~K}$ (Fig. 4A), because hopping becomes less efficient than tunneling when $k_{\mathrm{B}} T<<E_{\mathrm{a}}$. At low temperatures, therefore, the hopping mechanism is eliminated and the Fc moiety becomes part of the tunneling barrier in both directions of bias. 


\section{Conclusions}

To realize potential applications of SAM-based devices, the mechanisms of charge transport across these SAM-based junctions must be understood. This paper describes a method of fabricating arrays of seven SAM-based junctions per device that relies on the stabilization of liquid-metal electrodes in microchannels. This method achieves high post-fabrication yields (70-90\%) and junctions that are stable up to hundreds of cycles. Furthermore, this technique enables the measurement of $J(\mathrm{~V})$ characteristics as a function of the chemical structure of the SAM, with statistically large numbers of data, and as a function of temperature over the range of $90-293 \mathrm{~K}$. We believe that such studies are required to confirm that the characteristics of molecular devices are indeed dominated by the chemical composition of the SAMs, to discriminate artifact from real data, and to establish the mechanism of charge transport across SAMs.

We characterized two types of SAM-based junctions incorporating SAMs of $\mathrm{SC}_{\mathrm{n}}$ ${ }_{1} \mathrm{CH}_{3}(\mathrm{n}=12,14,16$, and 18$)$ and $\mathrm{SC}_{11} \mathrm{Fc}$. Junctions incorporating SAMs of $\mathrm{SC}_{11} \mathrm{Fc}$ have large rectification ratios of $R \approx 1.3 \times 10^{2}$, while those with $\mathrm{SAMs}$ of $\mathrm{SC}_{\mathrm{n}-1} \mathrm{CH}_{3}$ do not rectify $(R \approx 1-5)$. Our physical-organic study with statistically large numbers of data $(\mathrm{N}$ $=300-800)$ show that the rectification is due to the chemical structure of the SAM, and not caused by any of the other asymmetries of the junctions. Although molecular rectifiers have been reported before, ${ }^{13,14,15,16,18,20}$ no measurements of $J(\mathrm{~V})$ as a function of temperature have been conducted, leaving the mechanism of charge-transport unclear. Here, measurements of $J(\mathrm{~V})$ as a function of temperature clearly suggest a mechanism of charge transport across the $\mathrm{Ag}^{\mathrm{TS}}-\mathrm{SC}_{11} \mathrm{Fc} / / \mathrm{Ga}_{2} \mathrm{O}_{3} / \mathrm{EGaIn}$ junctions (Figure 5) consisting of 
tunneling supplemented by hopping at temperatures above $190 \mathrm{~K}$ and biases from $-0.6 \mathrm{~V}$ to $-1.0 \mathrm{~V}$. The charge can hop across the Fc moiety when the HOMO of the $\mathrm{Fc}$ overlaps with the Fermi levels of the electrodes, and thus reduces the width of the tunneling barrier, an event which occurs at negative bias but not positive bias. Thus, a difference in the mechanism of charge transport at opposite biases across the same junction is the basis of the large molecular rectification $\left(R \approx 1.3 \times 10^{2}\right)$ we observe in this system, and is potentially useful for constructing other molecular- or SAM-based, two-terminal devices with well-defined electronic functions.

\section{Methods}

Preparation of the SAMs. The synthesis of $\mathrm{HSC}_{11} \mathrm{Fc}$ followed a procedure described in the literature. ${ }^{49}$ The $\mathrm{HSC}_{\mathrm{n}-1} \mathrm{CH}_{3}$ (with $\mathrm{n}=12,14,16$, or 18, Sigma Aldrich) was purified by recrystallization from ethanol (under $\mathrm{N}_{2}$, three times) prior to its use in the formation

of the SAMs. We formed the SAMs at the $\mathrm{Ag}^{\mathrm{TS}}$ surfaces on glass (or on $\mathrm{Au}^{\mathrm{TS}}$ surface on glass for electrochemical studies) using 1-2 mM ethanolic solutions of the corresponding thiols under nitrogen over $16 \mathrm{~h}$.

Device Fabrication. We used photolithography, e-beam evaporation, and standard liftoff processes to form arrays of $100 \mathrm{~nm}$ thick Ag electrodes (10 $\mu \mathrm{m}$ wide and $5000 \mu \mathrm{m}$ long, with $500 \times 500 \mu \mathrm{m}^{2}$ square pads at their ends that facilitated addressing the electrodes with probes) on $\mathrm{Si} / \mathrm{SiO}_{2}$ wafers.

The optical adhesive (OA, Norland, No. 61) adheres strongly to $\mathrm{Si} / \mathrm{SiO}_{2}$. To minimize this interaction and to allow successful template stripping (TS), we 
functionalized the wafer with a monolayer of $1 \mathrm{H}, 1 \mathrm{H}, 2 \mathrm{H}, 2 \mathrm{H}-$ perfluorooctyltrichlorosilane $\left(\mathrm{Cl}_{3} \mathrm{Si}\left(\mathrm{CH}_{2}\right)_{2}\left(\mathrm{CF}_{2}\right)_{5} \mathrm{CF}_{3}\right.$, FOTS $)$ by gas phase deposition of the FOTS for one hour.

We applied a drop of OA as a liquid (as a film $\sim 0.1 \mathrm{~mm}$ thick) on the $\mathrm{Ag}$ electrodes, and positioned freshly cleaned glass slides (VWR microslides, $1 \mathrm{~mm}$ thick, rinsed with EtOH followed by 5 min cleaning in a plasma of air at 500 mTorr) on top of this drop of OA. We cured the OA for two hours in UV, during which the OA polymerized and adhered to both the Ag and the glass support, but not to the wafer with a monolayer of FOTS.

We separated the glass/OA/Ag composite from the $\mathrm{Si} / \mathrm{SiO}_{2}$ template by applying razor blade (almost) orientated in the plane of Si-wafer to one of the corners of the glass/OA/Ag composite. The sharp side of the razor blade was positioned against interface defined by the $\mathrm{OA}$ and the $\mathrm{Si} / \mathrm{SiO}_{2}$ wafer (with a monolayer of FOTS). Forcing the razor blade in between the layer of $\mathrm{OA}$ and the $\mathrm{Si} / \mathrm{SiO}_{2}$ wafer by pressing gently (in a direction parallel to the wafer) caused the razor blade to move in between the OA and the $\mathrm{Si} / \mathrm{SiO}_{2}$ wafer, and separated the glass $/ \mathrm{OA} / \mathrm{Ag}$ composite from the $\mathrm{Si} / \mathrm{SiO}_{2}$ template. Flipping the glass/OA/Ag composite exposed the ultra-flat silver electrodes that were originally in contact with the $\mathrm{Si} / \mathrm{SiO}_{2}$ wafer $(\mathrm{Fig} .1 \mathrm{G}) .{ }^{50}$ We immersed the electrodes in the ethanolic solutions of the thiols which we kept under an atmosphere of $\mathrm{N}_{2}$ within $5 \mathrm{~s}$ after template-stripping to minimize contamination of the metal surfaces.

Oxidation of the PDMS with an air-plasma (500 mTorr, $60 \mathrm{~s}$ ) prior to alignment improved the interaction of the $\mathrm{Ga}_{2} \mathrm{O}_{3}$ with the PDMS inside the microchannels. We positioned the microchannels ( $30 \mu \mathrm{m}$ wide, $30 \mu \mathrm{m}$ deep, and $8000 \mu \mathrm{m}$ long) in PDMS 
perpendicularly to the electrodes. The PDMS formed a contact with the OA/Ag ${ }^{\mathrm{TS}}$ surface that was strong enough to withstand further handling, and provided enough mechanical stability to withstand everyday handling in the lab; it also was sufficiently stable to perform $J(\mathrm{~V})$ measurements as a functions of temperature. We filled the microchannel with EGaIn by applying reduced pressure (500 Torr) to the outlet of the channel with a drop of $\mathrm{Ga}_{2} \mathrm{O}_{3} / \mathrm{EGaIn}$ at the inlet of the channel. To facilitate contact with the outlet of the channel in PDMS, we fitted a metal tube to one end of a rubber hose, the other end of which was connected to house vacuum. The vacuum was just enough to force the EGaIn through the channel. We believe that metallic EGaIn fills the channels and that, afterwards, a layer of $\mathrm{Ga}_{2} \mathrm{O}_{3}$ forms at the surface of EGaIn (see Additional Information). We applied and removed the vacuum gently, for we found that applying large forces on the PDMS (with the channel filled with $\mathrm{Ga}_{2} \mathrm{O}_{3} / \mathrm{EGaIn}$ ) resulted in shorts. During filling, the $\mathrm{Ga}_{2} \mathrm{O}_{3} / \mathrm{EGaIn}$ behaves as a liquid and readily fills the channel, but returns to its elastic state once the channel is filled and atmospheric pressure is restored. ${ }^{24}$ We hypothesize that the strong interaction of the $\mathrm{Ga}_{2} \mathrm{O}_{3}$ with the oxidized PDMS inside the microchannels resulted in mechanically stable structures (see Additional information).

Temperature-Dependent Measurements of $\boldsymbol{J}(\mathbf{V})$. In all of our measurement we biased the $\mathrm{Ga}_{2} \mathrm{O}_{3} / \mathrm{EGaIn}$ top-electrodes and grounded the $\mathrm{Ag}^{\mathrm{TS}}$ bottom-electrode. We measured $J$ as a function of $V$ at different values of temperature on junctions that had their $J(\mathrm{~V})$ characteristics within one log-standard deviation from the mean value of $J$. The temperature dependent measurements were performed with a probe station (Desert Cryogenics $)$ in vacuum $\left(1 \times 10^{-6}\right.$ bar $)$. The devices were cooled with liquid nitrogen from 
293 to $80 \mathrm{~K}$ over the course of three hours. We observed that during cooling the EGaIn solidified at temperatures of $240-260 \mathrm{~K}$. Reducing the pressure or cooling the devices did not result in short or open circuits. At intervals of $20 \mathrm{~K}$ we contacted the $\mathrm{Ag}^{\mathrm{TS}}$ and $\mathrm{Ga}_{2} \mathrm{O}_{3} / \mathrm{EGaIn}$ electrodes with the probes and recorded one $J(\mathrm{~V})$ curve while keeping the temperature constant. The electrodes were not contacted with the probes during cooling or heating of the devices.

Statistical Analysis. We analyzed SAM-based tunneling junctions fabricated with SAMs of $\mathrm{SC}_{\mathrm{n}-1} \mathrm{CH}_{3}$, using statistically large numbers of $J(\mathrm{~V})$ curves $(N=400-800$, Table S1) for each type of SAM. The yield of working devices was $70-90 \%$. We plotted the values of $J$ measured at all potentials ( -0.50 to $0.50 \mathrm{~V}$ in steps of $50 \mathrm{mV}$ ) in histograms and found that the values of $J$ were log-normally distributed and characterized by the logmean (eq. 7, where $\mathrm{N}$ is the number of values of $J$ ), rather than normally distributed and characterized by the mean (eq. 8).

$$
\begin{gathered}
<J>_{\log }=10^{z} \text { with } z=\frac{1}{N} \sum_{i=1}^{N} \log _{10}\left|J_{i}\right| \\
<J>=\frac{1}{N} \sum_{i=1}^{N} J_{i}
\end{gathered}
$$

To these histograms, we fitted Gaussians to obtain the $\log$-mean for $J$ and $\log$-standard deviation (see Additional Information). 


\section{References}

\footnotetext{
${ }^{1}$ A molecular device is truly molecular if it has at least one of the dimensions of a thickness of one molecule. Single molecule junctions are junctions that ideally contain only one molecule. Junctions based on self-assembled monolayers (SAMs) contain a
} large number of molecules $\left(10^{3}-10^{12}\right.$ depending on the size of the junctions) in the $x y$ plane, but are only one molecule thick in the $z$-direction.

${ }^{2}$ Collier, C. P.; Wong, E. W.; Belohradsky, M.; Raymo, F. M.; Stoddart, J. F.; Kuekes, P. J.; Williams, R. S.; Heath, J. R. Science 1999, 285, 391.

${ }^{3}$ Bang, G. S.; Chang, H.; Koo, J. -R.; Lee, T.; Advincula, R. C.; Lee, H. Small 2008, 4, 1399.

${ }^{4}$ Akkerman, H. B.; de Boer, B. J. Phys.: Condens. Matter 2008, 20, 013001.

${ }^{5}$ Fisher, G. L.; Walker, A. V.; Hooper, A. E.; Tighe, T. B.; Bahnck, K. B.; Skriba, H. T.;

Reinard, M. D.; Haynie, B. C.; Opila, R. L.; Winograd, N.; Allara, D. L. J. Am. Chem. Soc. 2002, 124, 5528 .

${ }^{6}$ Walker, A. V.; Tighe, T. B.; Cabarcos, O. M.; Reinard, M. D.; Haynie, B. C.; Uppili, S.;

Winograd, N.; Allara, D. L. J. Am. Chem. Soc. 2004, 126, 3954.

${ }^{7}$ Beebe, J. M.; Kushmerick, J. G. Appl. Phys. Lett. 2007, 90, 083117.

${ }^{8}$ Lau, C. N.; Stewart, D. R; Williams, R. S.; Bockrath, M. Nano Lett., 2004, 4, 569.

${ }^{9}$ Kim, T. -W.; Wang, G.; Lee, H.; Lee, T. Nanotechnology 2007, 18, 315204.

${ }^{10}$ Selzer, Y.; Cabassi, M. A.; Mayer, T. S.; Allara, D. L. J. Am. Chem. Soc. 2004, 126, 4052. 
${ }^{11}$ Li, X. L.; Hihath, J.; Chen, F.; Masuda, T.; Zang. L.; Tao, N. J. J. Am. Chem. Soc. 2007, 129, 11535.

${ }^{12}$ Aviram, A.; Ratner, M. A. Chem. Phys. Lett. 1974, 29, 277.

${ }^{13}$ Metzger, R. M. Acc. Chem. Res. 1999, 32, 950.

${ }^{14}$ Lenfant, S.; Krzeminski, C.; Delerue, C.; Allan, G.; Vuillaume, D. Nano Lett. 2003, 3, 741.

${ }^{15}$ Ashwell, G. J.; Urasinska, B.; Tyrrell, W. D. Phys. Chem. Chem. Phys. 2006, 8, 3314.

${ }^{16}$ Chen, X.; Jeon, Y. -M.; Jang, J. -W.; Qin, L.; Huo, F.; Wei, W.; Mirkin, C. A. J. Am. Chem. Soc. 2008, 130, 8166.

${ }^{17}$ Böhme, T.; Simpson, C. D.; Müllen, K., Rabe, J. P. Chem. Eur. J. 2007, 13, 7349.

${ }^{18}$ Chabinyc, M. L.; Chen, X.; Holmlin, R. E.; Jacobs, H.; Skulason, H.; Frisbie, C. D.;

Mujica, V.; Ratner, M. A.; Rampi, M. A.; Whitesides, G. M. J. Am. Chem. Soc. 2002, 124,11730

${ }^{19}$ Love, J. C.; Estroff, L. A.; Kriebel, J. K.; Nuzzo, R. G.; Whitesides, G. M. Chem. Rev. 2005, 105, 1103.

${ }^{20}$ Metzger, R. M. Chem. Rev. 2003, 103, 3803.

${ }^{21}$ Selzer, Y.; Cabassi, M. A.; Mayer, T. S.; Allara, D. L. Nanotechnology 2004, 15, S483.

${ }^{22}$ Chiechi, R. C.; Weiss, E. A.; Dickey, M. D.; Whitesides, G. M. Angew. Chem. Int. Ed. 2008, $47,142$.

${ }^{23}$ Nijhuis, C. A; Reus, W. F.; Whitesides, G. M. J. Am. Chem. Soc. 2009, 131, 17814.

${ }^{24}$ Dickey, M. D.; Chiechi, R. C.; Larson, R. J.; Weiss, E. A.; Weitz, D. A.; Whitesides, G. M. Adv. Funct. Mater. 2008, 18, 1097. 
${ }^{25}$ Weiss, E. A.; Chiechi, R. C.; Kaufman, G. K.; Kriebel, J. K.; Li, Z.; Duati, M.; Rampi, M. A.; Whitesides G. M. J. Am. Chem. Soc. 2007, 129, 4336.

${ }^{26}$ Black, A. J.; Paul, K. E.; Aizenberg, J.; Whitesides, G. M. J. Am. Chem. Soc. 1999, $121,8356$.

${ }^{27}$ Zrnic, D.; Swatik, D. S. J. Less-Common Met. 1969, 18, 67.

${ }^{30}$ Venkataraman, L.; Klare, J. E.; Nuckolls, C.; Hybertsen, M. S.; Steigerwald, M. L. Nature 2006, 442, 7105.

${ }^{31}$ McCreery, R. L. Chem. Mater. 2004, 16, 4477.

${ }^{32}$ Slowinski, K.; Fong, H. K. Y.; Majda, M. J. Am. Chem. Soc. 1999, 121, 7257.

${ }^{33}$ Engelkes, V. B.; Beebe, J. M.; Frisbie, C. D. J. Am. Chem. Soc. 2004, 126, 14287.

${ }^{34}$ Reus, W. F. Nijhuis, C. A.; Barber, J.; Cademartiri, L.; Mwagni, M.; Whitesides , G. M.; manuscript in preparation.

${ }^{35}$ Lee, S. -Y.; Tung, H. -W.; Chen, W. -C.; Fang, W. IEEE Photon. Technol. Lett. 2006, $18,2191$.

${ }^{36}$ Menke, Y.; Peltier-Baron, V.; Hampshire, S. J. Non-Cryst. Solids 2000, 276, 145.

${ }^{37}$ Yamaga, M.; Víllora, E.G.; Shimamura, K.; Ichinose, N.; Honda, M.; Phys. Rev. B 2003, 68, 155207.

${ }^{38}$ Lide, D. R. Handbook of Chemistry and Physics CRC Press, Inc.: Boca Raton, 1996.

${ }^{39}$ Koster, J. N. Cryst. Res. Technol. 1999, 34, 9.

${ }^{46}$ Müller-Meskamp, L.; Karthäuser, S.; Zandvliet, H. J. W.; Homberger, M.; Simon, U.; Waser, R. Small 2009, 5, 496.

${ }^{47}$ Stadler, R.; Geskin, V.; Cornil, J. J. Phys.: Condens. Matter. 2008, 20, 374105.

${ }^{49}$ Creager, S. E.; Rowe, G. K. J. Electroanal. Chem. 1994, 370, 203. 
${ }^{50}$ The yield of the template-stripping step was nearly $100 \%$. We observed occasionally that the silver electrodes had defects. 


\section{Acknowledgements}

The Netherlands Organization for Scientific Research (NWO) is kindly acknowledged for the Rubicon grant (C.A.N.) supporting this research. Prof. Hongkun Park is gratefully acknowledged for allowing us to conduct the temperature dependent $J(\mathrm{~V})$ measurements in his laboratory. We acknowledge NSF (grant CHE-05180055) for funding.

\section{Author Contributions}

C.A.N. and M.D. designed and fabricated the devices. C.A.N. performed the $J(\mathrm{~V})$ measurements and developed the model to explain all observations. J.B. and W.F.R. repeated the fabrication, and measurements of $J(\mathrm{~V})$, of devices with SAMs of $\mathrm{SC}_{12}$ and $\mathrm{SC}_{18}$ and performed the AFM analysis. All authors discussed the results, commented on the manuscript, and co-wrote the paper.

\section{Additional information}

Supplementary information accompanies this paper on www.nature.com/naturematerials. Reprints and permissions information is available online at http://npg.nature.com/Reprintsandpermissions. Correspondence and requests for materials should be addressed to G.M.W. 